\title{
Auf schnellem Weg zum Impferfolg
}

\section{Yvonne Gilli}

Dr. med., Präsidentin der FMH

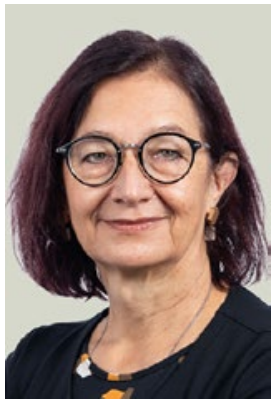

Als der Arzt Edward Jenner im Jahr 1796 erstmals einen Jungen mit Hilfe von Kuhpockensekret gegen die Pocken immunisierte, war dies ein Meilenstein der Medizingeschichte. Den Pocken, die schon die alten Ägypter gequält hatten, konnte vorgebeugt werden. Seither haben Impfungen Millionen Menschenleben gerettet sowie Krankheiten und deren Folgeschäden verhindert. Die Ausrottung der Pocken war jedoch erst 1980 erreicht, nachdem ein WHO-Programm einen koordinierten Einsatz des Impfstoffes sichergestellt hatte. Die Corona-Krise zeigt, wie viel schneller die Welt geworden ist: Nicht nur Viren - auch wissenschaftliche Erkenntnisse werden rasant global gestreut. In der Schweiz dauerte es keine zehn Monate von der ersten gemeldeten Covid-19-Infektion [1] bis zur Zulassung eines marktreifen mRNA-Impfstoffes [2]. Trotz äusserst anspruchsvoller Logistik und einiger Schwierigkeiten konnten - Stand 14.2.2021 - bereits 542196 Impfdosen verabreicht werden. Immer mehr Risikopatienten sind geschützt, ohne sich dafür isolieren zu müssen. Die Impfbereitschaft in der Bevölkerung ist gross und wächst - und mit ihr die Hoffnung auf eine Bewältigung der Pandemie.

In der Schweiz dauerte es keine zehn Monate vom ersten Covid-19-Fall bis zur Zulassung eines marktreifen mRNA-Impfstoffes.

Diese schnelle Entwicklung sorgt aber nicht nur für Anerkennung. Sie verunsichert auch viele Menschen. Vor allem in den sozialen Medien, die Randgruppen unverhältnismässige Plattformen bieten, verbreiten sich falsche oder ohne Kontextwissen irreführende Informationen. Dies befeuert Diskussionen, die leicht zur Entdifferenzierung und Polarisierung führen. Doch moralischer Druck und Verurteilung dürfen nicht an die Stelle einer sachlichen Auseinandersetzung und Abwägung treten. Die Medizin darf sich auch nicht für eine solche Inszenierung von «Gut» gegen «Böse» instrumentalisieren lassen. Ihre Kernkompetenz ist es, Fachinformationen zur Verfügung zu stellen und sie im Lichte der Situation individueller $\mathrm{Pa}$ tientinnen und Patienten zu beurteilen.

Selbstverständlich begrüsst die FMH als Berufsverband der Ärzteschaft die Covid-19-Impfung als neues Instrument im Kampf gegen die Pandemie und hat auch von Beginn an ihre tatkräftige Unterstützung zu- gesichert [3]. Die Impfbereitschaft von Ärztinnen und Ärzten ist klar überdurchschnittlich, und es steht auch jedem Menschen frei, die eigene Impfung öffentlich zu machen. Entscheidend für unsere Rolle als Ärztinnen und Ärzte ist aber, dass es bei den Covid-19-Impfungen nicht um uns geht, sondern um unsere Patienten und Patientinnen. Unsere Aufgabe ist nicht, ihnen unsere Meinung «einzuimpfen», sondern ihnen die verfügbaren Informationen verständlich zu vermitteln, sie also «aufzuklären» und damit zu einer Entscheidung zu be-

Unsere Aufgabe ist es, unseren Patienten die verfügbaren Informationen $z u$ vermitteln und sie so zu einer Entscheidung zu befähigen.

fähigen. Angesichts der aktuellen Erkenntnisse über Risiko und Nutzen ist zu erwarten, dass diese Aufklärung meistens einen Entscheid für die Impfung nach sich ziehen wird. Dies zeigt auch die wachsende Impfbereitschaft der Bevölkerung. Es wird aber auch Patienten und Patientinnen geben, die sich gegen eine Impfung entscheiden - und dafür Gründe haben, deren Bewertung uns nicht zusteht. Die ärztliche Ethik verlangt, die freie Entscheidung des einzelnen Patienten zu schützen. Es untergräbt auch den Schutz persönlicher Rechte, wenn ein öffentliches Bekenntnis zur eigenen Impfung eingefordert wird: Niemand möchte z.B. Kontraindikationen offenlegen müssen, um einer moralischen Verurteilung zu entgehen.

Bislang kommen wir auf dem Weg zum Impferfolg sehr schnell voran. Die Wissenschaft hat diesen Weg geebnet. Als Ärztinnen und Ärzte zeigen wir unseren Patientinnen und Patienten auf, was dieser Weg für sie bedeutet - schubsen sie ihn aber nicht entlang. Wenn es jetzt noch gelingt, die nationale und internationale Verfügbarkeit und Verteilung der Impfstoffe zu verbessern und die Impfungen den Mutationen schnell genug anzupassen, dürfen wir hoffen, dass Covid-19 die Menschen deutlich kürzer plagen wird als andere Infektionskrankheiten zuvor.

Literatur

1 Medienmitteilung BAG, 25.2.2020, Neues Coronavirus COVID-19: Erster bestätigter Fall in der Schweiz. www.bag.admin.ch/bag/de/ home/das-bag/aktuell/medienmitteilungen.msg-id-78233.html

2 Medienmitteilung swissmedic, 19.12.2020, Swissmedic erteilt Zulassung für den ersten Covid-19-Impfstoff in der Schweiz. www. swissmedic.ch/swissmedic/de/home/news/coronavirus-covid-19/ covid-19-impfstoff_erstzulassung.html

3 Medienmitteilung FMH, 13.1.2021. Die FMH unterstützt die Impfung gegen COVID-19. 